\title{
The Caring Campus Project Overview
}

\author{
Heather Stuart \\ Queen's University \\ Shu-Ping Chen \\ University of Alberta \\ Terry Krupa, Tasha Narain, and Salinda Horgan \\ Queen's University \\ Keith Dobson \\ University of Calgary \\ Sherry Stewart \\ Dalhousie University
}

\begin{abstract}
The Caring Campus project was a three-year intervention research project funded by Movember Canada that fostered new awareness regarding the interconnection between gender, mental health, and substance (specifically alcohol) misuse on three university campuses in Canada, and encouraged new approaches to promote young men's health. In this project, we demonstrated that male students are willing to assume leadership roles to promote mental health and healthier alcohol use to their peers and enact a social agenda for change. Empowerment strategies encouraged male students to enlist like-minded peers to advance men's mental health and transform campus drinking cultures, including countering genderbased ideals and norms associated with mental health problems and substance misuse. There is now great potential to influence the way in which other post-secondary institutions approach mental wellness and substance misuse using the Caring Campus model, which uses student empowerment to catalyze change.
\end{abstract}

Keywords: alcohol misuse, intervention research, male mental health, post-secondary students

Heather Stuart, Department of Public Health Sciences, Queen's University, Kingston, Ontario; Shu-Ping Chen, Department of Occupational Therapy, University of Alberta; Terry Krupa, School of Rehabilitation Therapy, Queen's University, Kingston, Ontario; Salinda Horgan, Centre for Health Services and Policy Research, Queen's University; Keith Dobson, Department of Psychology, University of Calgary, Calgary, Alberta; Sherry Stewart, Department of Psychology, Dalhousie University, Halifax, Nova Scotia.

Tasha Narain is currently at the Canadian Agency for Drugs and Technology in Health, Ottawa, Ontario.

This research was supported in part by a grant from the Movember Foundation.

Correspondence concerning this article should be addressed to Heather Stuart, Professor and Bell Canada Mental Health and Anti-Stigma Research Chair, Queen's University, Kingston, Ontario, Canada, K7L 3N6. Email: heather.stuart@queensu.ca

The Caring Campus Toolkit is an integral part of the Caring Campus Project. The Toolkit can be accessed at https://doi.org/10.7870/ cjemh-2018-018 


\section{RÉSUMÉ}

Initiative financée par Movember Canada, Caring Campus était un projet de recherche interventionnelle d'une durée de trois ans qui visait à créer un environnement favorable à une nouvelle prise de conscience des liens existant entre le genre, la santé mentale et l'abus de substances (plus particulièrement l'alcool) sur trois campus universitaires au Canada et à mettre en œuvre de nouvelles approches pour promouvoir la santé chez les jeunes hommes. Dans le cadre de ce projet, nous avons fait la démonstration que les étudiants de sexe masculin sont prêts à assumer un rôle de leader pour promouvoir l'importance de la santé mentale et des habitudes plus saines en matière de consommation d'alcool auprès de leurs pairs et à mettre en œuvre un programme social porteur de changements. Les stratégies d'autonomisation ont incité les étudiants de sexe masculin à faire appel à des pairs animés du même esprit qu'eux pour promouvoir la santé mentale des hommes et transformer les comportements culturels en matière de consommation d'alcool sur les campus, notamment en luttant contre les idées préconçues et les normes sexospécifiques associées aux problèmes de santé mentale et d'abus de substances. Il existe à présent un potentiel énorme pour influencer la manière dont les autres établissements d'enseignement postsecondaire abordent les thématiques du bien-être mental et de l'abus de substances à l'aide du modèle Caring Campus, lequel repose sur la responsabilisation des étudiants pour catalyser le changement.

Mots clés : consommation abusive d'alcool, recherche interventionnelle, santé mentale des hommes, étudiants de niveau postsecondaire

The Caring Campus project was a three-year demonstration project that focused on student mental health and substance (specifically alcohol) misuse in three university campuses in Canada. It was funded by Movember Canada. As with many research projects, the impetus came from a personal experience of one of the principal investigators, and a colleague's son who did not make a smooth transition from high school to university life. He had been skipping classes and missing assignment deadlines for the better part of an academic term. When things finally came to a head, it became clear that he had been misusing substances and this had induced a serious psychotic episode. This occurrence shocked his parents, who had believed he was doing well in classes and enjoying university life. Although his friends and school peers knew something was wrong, they were unsure whether or how to intervene. We wondered if a more caring campus culture - one that did not promote alcohol and other substance misuse, but where young people could be empowered to respond when problems presented - might have prevented this situation.

Mental health on university campuses has received much attention in recent years. According to the American College Health Association's national college survey (NCHA), Canadian Edition 2016 Spring Executive Summary, $42.2 \%$ of Canadian college students indicated their academic performance had been affected in the past 12 months because of stress. Almost a third (32.5\%) identified anxiety and a fifth (20.9\%) identified depression as affecting their academic performance. With respect to stress, $50.0 \%$ of males and $64.8 \%$ of females reported "more than average" to "tremendous" levels of stress (American College Health Association, 2016). Additionally, $89.5 \%$ of students reported feeling overwhelmed during the last year, and $44.4 \%$ of students reported being so depressed they had difficulty functioning.

Excessive drinking is also a significant concern in post-secondary populations (Wechsler \& Nelson, 2008; Blank, Connor, Gray, \& Tustin 2015; Wicki, Kuntsche, \& Gmel, 2010). The NCHA survey shows the majority 
of students ( $82.3 \%$ male and $85.6 \%$ female) drink. Of those that reported drinking, $54.8 \%$ of men and $44.7 \%$ of women drank five or more drinks the last time they socialized. Additionally, $4.5 \%$ identified alcohol use and $2.2 \%$ identified drug use as affecting academic performance. Approximately one fifth $(20.9 \%$ males and $16.5 \%$ females) reported having used marijuana in the last 30 days (American College Health Association, 2016). Other studies conducted in Canada and elsewhere show that almost a third of undergraduate students meet the criteria for hazardous or harmful drinking patterns as measured by a standardized screening test (Adlaf, Demers, \& Gliksman, 2005), 13.5\% use cannabis (Arbour-Nicitopoulos, Kwan, Lowe, Taman, \& Faulkner, 2010), and 17\% misuse prescription stimulants (Benson, Flory, Humphreys, \& Lee, 2015).

Despite increased awareness of the importance of mental health promotion on university campuses, in most parts of the country alcohol and other substance misuse has not been part of this dialogue in any meaningful or integrated way. A notable exception to this is the Healthy Minds | Healthy Campuses initiative in British Columbia where substance use concerns have been part of the discussion and situated in the context of mental health promotion for more than a decade (see healthycampuses.ca). Mental wellness initiatives and substance reduction programs are often managed separately, even though substance misuse and mental health problems influence one another and share many of the same determinants (Centre for Addiction and Mental Health, 2013). For example, many students consume alcohol and other drugs to cope with stress, improve mood, or distract themselves from their current circumstances (Keyes, Hatzenbuehler, Grant, \& Hasin, 2012; Reavley \& Jorm, 2010). The converse is also true. Substance misuse is a major contributing factor to a host of negative outcomes including unemployment, poor health, accidents, suicide, mental illness, and decreased life expectancy (Das, Salam, Arshad, Finkelstein, \& Bhutta, 2016).

The goals of the Caring Campus Project were to engage first-year university students to increase awareness about the relationship between misuse of substances and mental health problems. Our specific focus was on first-year male students, the rationale for which is described in more detail below. We expected that the initiative would allow male students to self-manage the risks associated with substance misuse, reduce the stigma attached to substance misuse and mental health problems by creating more open dialogue, and create a more supporting and caring campus environment. We addressed these goals at three levels. At the individual level, we encouraged caring about the self, awareness raising, and prevention. At the collective level, we encouraged caring for others, destigmatization, and increasing social responsibility. At the community level, we encouraged the development of a caring campus community by building a more supportive and inclusive campus culture. As the project unfolded, we narrowed our focus to alcohol misuse as our own data showed it was the most pressing issue.

\section{Our Focus on First-Year University Men}

We focused the Caring Campus Project on males for a number of reasons. Males are significantly more likely to misuse substances, including alcohol, than women. They consume greater amounts of alcohol, and drink more frequently (Blank, Connor, Gray, \& Tustin, 2015; Wicki, Kuntsche, \& Gmel, 2010; Adlaf, Begin, \& Sawka, 2005; Stone, Becker, Huber, \& Catalano, 2012; Dowson, Schneider, Fletcher, \& Bryden, 2007), even when factors such as education, marital status, and income are taken into account (Lalomiteanu, Adlaf, Mann, \& Rehm, 2011). According to the Canadian Addiction Survey (Health Canada, 2008), 24.2\% of Canadian males aged 20-24 have reported heavy and frequent drinking patterns in the past year, compared 
to $12.7 \%$ of same-aged females. In the Canadian Tobacco Alcohol and Drugs (CTADS), 2015 survey, 28\% of young adult drinkers exceeded the guidelines for low-risk alcohol use. Males were more likely to exceed these guidelines (22\% males compared to $18 \%$ females; Government of Canada, 2017).

As is true of males in general, male post-secondary students are also more likely to misuse substances, particularly alcohol. For example, in one Canada-wide study of post-secondary students, male undergraduates reported drinking significantly more often than females (1.7 times per week versus 1.0 times per week, respectively), and a higher quantity of drinks ( 8.9 drinks per week, versus 4.5; Adlaf, Demers, \& Gliksman, 2005). Data from the public use files of the Canadian Tobacco Alcohol and Drugs 2015 Survey shows that $31.6 \%$ of male college-aged young adults (aged 18-25 years) drank an average of five or more drinks at a usual sitting compared to $16.2 \%$ of females. In addition, $5.9 \%$ of young adult males drank daily compared to $2.4 \%$ of females (Government of Canada, 2017).

Similar patterns have been reported elsewhere. For example, in the United States White, Kraus and Swartzwelder (2006) reported two-week histories of binge drinking among 10,424 first-year students at 14 schools across the United States during 2003. One in five males and one in 10 females consumed twice the binge level threshold (10+ drinks) at least once in the two weeks prior to the survey. Males were more likely than females to drink at levels that were two or three times the binge threshold. The United States National Survey Results on Drug Use (Johnston, O’Malley, Bachman, Schulenbergt, \& Miech, 2016) reports that having 10 or more drinks in a row in the two weeks prior to the survey was three times higher among college males (22\%) compared to females (7\%). Males were also more likely to report being drunk in the past 30 days (44\% vs. 34\%, respectively). In France, a survey of 3,266 college students found that two-thirds engaged in binge drinking occasionally or frequently. Frequent binge drinking was significantly more common in male students (24.6\%) compared to female students (7.4\%). In Japan, Yoshimoto and colleagues (2017) surveyed 2,177 college students. Over half (56.8\%) of men and 47.8\% of women were classified as binge drinkers. Alcohol related injuries were experienced in the past year by $6.6 \%$ of male students and $2.7 \%$ of female students.

The transition from high school to university marks a distinct developmental period characterized by increased identity exploration, rapid behavioural change, and heavy alcohol consumption. Alcohol use is already prevalent among students in their final year of secondary school, and the gendered variations in alcohol use (with higher prevalence among men) increases with grade level (Leatherdale \& Burkhalter, 2012). Risky drinking usually increases during the first few weeks of campus life as students meet new people and join new social groups. In addition, the first week of orientation may promote alcohol use and misuse. While drinking is not permitted during orientation events on many campuses, students often gather in residences, local pubs, or other places to party late into the evening after the day's orientation events have closed. Perceptions about normative drinking behaviour are reinforced during this time and predict high-risk alcohol consumption during the first year and beyond. High-risk patterns of drinking can lead to academic problems, unprotected sexual behaviour, injury, and even death, as well as a host of other adverse consequences (Scott-Sheldon, Carey, Elliott, Garey, \& Carey, 2014). Consequently, first-year post-secondary males are an important target for prevention efforts. 


\section{The Importance of an Empowerment Framework}

Conventional public health approaches emphasize disease prevention through lifestyle change using "top down" approaches. These approaches use centralized policies and organizational frameworks to provide education and influence public behaviour. An alternate model emphasizes community empowerment and advocacy using "bottom up" approaches. In such approaches health promotion agencies and community developers support community members in the identification of issues that are important in their lives and assist them to develop strategies to resolve these issues. Community empowerment becomes an explicit proximal goal, with the idea that distal outcomes, such as enhanced social justice and improved health, will follow (Laverack \& Labonte, 2000; Downey, Anyaegbunam, \& Scutchfield, 2009).

Mental health advocates have argued that empowered consumers benefit more from mental health services than those who are passive recipients. Empowerment is conceptualized as a process by which power is developed, which then allows individuals, collectives, and communities to act on their own behalf (Rogers, Chamberlain, Ellison, \& Crean, 1997; Clark \& Krupa, 2002; Chen et al., 2017). Empowermentbased health promotion activities allow people to control their own lives and their communities, and to improve their personal and community health. Empowerment requires that community members are given the opportunity to name their issues using their own language and understandings, discuss possible actions, and take those actions (Downey, Anyaegbunam, \& Scutchfield, 2009). Empowerment improves individual self-esteem and self-efficacy and promotes community action and confidence to affect change (Corrigan, Faber, Rashid, \& Leary, 1999).

First-year university men are not often viewed as disempowered. However, in the context of the Caring Campus Project, we noted that young men on all three campuses were not engaged in either formal or informal health and wellness activities. In all of the student wellness services, females were more likely to report mental health concerns. This gender discrepancy in participation in, and access to, formal health and well-being activities and resources has been reported in the literature. Males have been found to be less likely to ask for help (Ibrahim, Kelly, Adams, \& Glazebrook, 2013) and more likely to report feelings of self-stigma regarding help-seeking for mental health concerns, which is a major barrier to accessing support (Eisenberg, Downs, Golberstein, \& Zivin, 2009; Oliffe et al., 2016). As such, we observed that males were largely absent from mental health and wellness groups including peer support groups (which were predominantly female-led), less likely to attend student wellness services when they had problems, and largely absent from conversations about mental health and wellness. Indeed, we knew of no male support groups, either formal or informal, operating on our study campuses. In these ways, male students experienced a form of health inequity that needed to be addressed, without undermining the very real health and well-being consequences that female students can and do experience in relation to substance use and mental health. From our perspective, empowerment meant creating a campus environment where young men could take an interest and have a voice in issues pertaining to male mental wellness and alcohol misuse, and could affect social action and cultural change that was inclusive of all students.

Consistent with an empowerment framework, we adopted a participatory, community development approach. There is a growing recognition that local actors who design and implement grassroots health initiatives are more likely to bring about change. Their peers are more likely to change their own behaviours when they see trusted colleagues leading the way. It also means that activities are driven by local knowledge 
(Campbell \& Jovchelovitch, 2000). Youth involvement in programming is also becoming more common, though roles may vary between genuine partners to token spokespeople. Empowerment frameworks assume that youth are assets, and that they will solve community problems when enabled to do so (Marko \& Watt, 2011). Rather than viewing community development as something that is planned for and implemented to others, it becomes something that the potential beneficiaries own and implement for themselves (Mathie \& Cunningham, 2005). The Caring Campus Project was no exception to other youth-led and adult-guided interventions (Marko \& Watt, 2011), although the extent to which researchers directly guided youth varied from setting to setting and intervention to intervention. In most situations, researchers functioned in a consultative capacity, working with the assumption that both groups (students and researchers) had expertise to bring to the table. The students' expertise was in knowing what their colleagues would accept and what would attract them to a particular intervention. Researchers brought expertise in terms of knowledge about the research literature concerning best practice approaches and methods for evaluating the effectiveness of intervention strategies.

As a stand-alone, fully funded intervention research project, The Caring Campus Project had considerable latitude to undertake a participatory approach. We recruited young men and encouraged them to use their base of associations and social networks to mobilize change that was both interesting and important to them. Change was instigated and driven by the young men who were recruited for the project and who were given autonomy to develop interventions that were consistent with their local campuses. This meant that interventions and activities were not the same or rolled out in the same way at each campus. This allowed the young men to tailor interventions to the local context of their campuses and take advantage of local opportunities and initiatives.

We also operated largely outside of traditional organizational structures, which made it possible for the students to use approaches that would not normally be part of the broader university's repertoire of mental wellness activities or enforcement tools around drinking, though the extent to which the Caring Campus Project was entirely separate from university administration varied across universities. The activities of the students remained largely autonomous, but the researchers developed partnerships with the university administration and provided a bridge to existing activities. This provided an opportunity to educate administrators about the importance of harm reduction activities and divorced the project from the punitive, sanction-oriented stance often associated with Canadian universities' administrative responses to alcohol misuse.

\section{Choice of Campuses}

The choice of campuses was in part because we had strong investigative teams and collaborators at each campus that were in a position to shepherd this project in their respective locations. In all three campuses, student mental health and wellness was an important priority. In addition, locations reflected three potentially different campus drinking cultures. One campus was a large commuter campus in the West where few students stayed in residence and where the campus was a considerable distance from the city centre and city night life. There were several drinking establishments on campus that students could frequent and these were operated by the student union; however, students tended to leave the campus for the commute home at the end of each day. The second campus was a smaller, centrally located campus within walking distance of the city centre with its multiple pubs and restaurants that students frequented. Most first-year 
students lived in residence, where excessive drinking was prevalent. The third campus was a smaller Eastern university situated across several campus locations. First-year students attending this campus primarily lived in residences. In addition, there were several fraternities and sororities.

\section{Our Strategies}

Campus drinking cultures have a direct effect on the attitudes and behaviours of students toward alcohol misuse. A "drinking culture" has been defined as the collection of attitudes, expectations, and behaviours that influences drinking norms (Ahern, Galea, Hubbard, Midanik, \& Syme, 2008). The Caring Campus Project was particularly focused on understanding drinking cultures that promoted excessive drinking norms in university environments. We also included social and organizational structures (such as the presence of bars on or near campus, access to alcohol for minors, alcohol-related events on or near campus) as part of our understanding of drinking cultures. Excessive drinking and its negative mental and physical consequences are not only accepted as part of the typical college experience (Reis \& Riley, 2008; Misch, 2010), but may even be championed. For example, Valdivia and Stewart (2005) have shown that cognitive and behavioural impairment from drinking (typically considered by researchers to be negative alcohol expectancies) can be evaluated positively by students. Evaluating these consequences as positive predicted heavy drinking.

To fully address mental wellness on university campuses, it is necessary to counter a culture that promotes excessive drinking and encourage universities to expand their traditional roles from sanctions and services to catalysts for cultural change (Cooper, 1999). A central factor that facilitates student alcohol misuse is the desire for social acceptance by peers and classmates. Misch (2010) has argued that a key response should be to empower students and give them the authority to confront unhealthy drinking norms and behaviours through peer-led initiatives.

The Caring Campus Project assumed that universities can foster supportive campus cultures, which in turn can empower students to redefine the parameters of acceptable drinking. We adopted a student empowerment model (described above) to open dialogue about the interconnections between mental health problems and alcohol misuse, engage male students to take a lead in critically assessing the campus drinking culture, and to help male students identify and manage the risks associated with alcohol misuse in themselves and others. By opening dialogue and frank discussions, students sought to reduce the stigma attached to mental health and alcohol misuse, and to create a more supportive and caring campus environment where it became more permissible to intervene to support peers who were having mental health and/or substance use problems. We focused on first-year undergraduate male students because they are at the greatest risk of alcohol misuse during this difficult transition year. The project combined four evidence-informed strategies, even though all had not been systematically and specifically applied to address substance use issues. These strategies provided the broad operating parameters for activities at each campus - activities that differed in their implementation according to the student-led interests and activities. They included:

Student summits. Student summits were meetings of identified student leaders. These summits facilitated knowledge exchange about substance misuse in relation to mental wellness and the availability of local resources. Students attending the summits heard other young men's personal experiences with mental illnesses and substance misuse and thought about how to innovate solutions and potential approaches to 
address the problem on their respective campuses. Summits also empowered the students to work together to open a constructive dialogue with other students surrounding male substance misuse and mental wellness, and to engage mental health groups on campus to highlight the role of substance misuse and the need for gender-sensitive or gender-transformative approaches to interventions.

Contact-based education. This approach to education centres on the stories of students who have lived experience. Students share their actual experiences (directly and through video clips) about how they lived with a mental health issue, the real problems they experienced, and how they came to experience well-being. Though contact-based education has been widely used to reduce mental health-related stigma and improve help-seeking (Stuart, Koller, Christie, \& Pietrus, 2011; Corrigan, Morris, Michaels, Rafacz, \& Rusch, 2012; Chen et al., 2017), contact-based education had not been used before to address the stigma surrounding substance misuse. We used it to raise awareness about the effects of stigma and to help bridge the gap between awareness and action. Two key challenges were to identify the important components of a substance use recovery story that would resonate with first-year male students, and to find male students who were comfortable speaking in public about previous substance misuse and mental health problems. For example, at one university, students specifically focused on a "Pro-social" brand and stories emphasized how others had assisted in the recognition of their problem and the path back from substance misuse to well-being.

Substance use continuum. We adapted the Mental Health Continuum Model developed by Canada's Department of National Defence (Zamorski, Guest, Bailey, \& Garber, 2012) to depict a continuum of substance use patterns from low risk, moderate risk, high risk, to illness. This continuum was conceived as a self-assessment tool (rather than a quantitative risk scale) for students to reflect upon and self-monitor their substance use behaviours and those of their peers in order to reduce risks and promote wellness. Our original intent was to build an application that could be used by students on their smart phones or on a website to self-identify and self-monitor their substance use behaviours. However, focus groups with students indicated that they would be unlikely to use an application in this way. Therefore, we used conventional modes of paper distribution, with and without education and dialogue. More detailed information on the Substance Use Wellness Tool can be found in this special issue (see Chen et al.).

Social norms approach. Social norms interventions focus on how perceptions about cultural norms (combined with the need to fit into a new peer culture) can be changed to influence individual substance use (Hagman, Noel, \& Clifford, 2007). This component of the project (described elsewhere in this special issue by Narain et al.) collected local survey data to identify and disseminate information about actual substance use patterns on campus, perceptions, or positive social norms.

\section{Implementation}

The project was implemented in three phases. In the first phase, the lead university gathered focus group information about patterns of student drinking and drinking norms. This information was necessary to adapt the interventions to incoming freshmen. Interventions were field tested to determine their feasibility in the second phase of the project. Finally, the interventions were disseminated to the two partnering university sites in the third phase, to determine their replicability. To the best of our knowledge, this was the first health promotion project to focus on male university students and the first to focus on substance misuse as a means 
of improving mental health. The project integrated interventions that were effective in the mental health field (the mental health continuum, contact-based education, and student summits) with interventions that had demonstrated some success in the substance use field and other domains (e.g., social norms interventions). It was also multi-level, so addressed individual behaviours (through the substance use wellness tool), collective actions (through the student summits) and campus community level (through social norms interventions, contact-based education, and student-led interventions emerging from summit activities).

\section{The Creation of Social Identities}

The social identity literature emphasizes that health-related behaviours are shaped by collectively negotiated social identities (Campbell \& Jovchelovitch, 2000). In the case of the Caring Campus Project the pivotal identities were masculine drinking identities. A key first step for the group of students on each campus was to create their own "empowered identities" or "brands" that were used to provide a banner for their subsequent activities and raise levels of recognition from other campus groups. Each of the identities was rooted in the social and cultural community of the respective campuses. For example, at one university the phrase, "For the Boys" had been used to depict heavy drinking, womanizing, and rabble rousing. The group here decided that they would reclaim and rebrand the meaning of the term to reflect a community of men who looked out for each other, made sure that they got home safely, and looked out for their female colleagues. Another group chose "Man Up" as their brand to indicate that it was time for men to ask for help when needed, and to reconceptualize drinking behaviours in a way that did not result in harm. Finally, the third group chose 'PRO-social' as their brand in order to promote a PROsocial environment with the goals of encouraging PROactive decisions, PROmoting a healthy, compassionate and informed campus, and imPROving campus-wide accessibility and awareness of student wellness resources. Each of these brands was indicative of a shared view of the world consistent with the overall aims of the Caring Campus initiative but were deeply rooted within local history and culture.

\section{Overview of Project Activities}

An online presence and use of social media were cornerstones of all three campus groups. Websites offered practical tips that could help students manage their alcohol use and promote physical and mental health. These websites provided evidence-based drinking norms, tips for responsible drinking, sleep, stress management, social life, physical activities, sex and relationships. Information on local resources was provided, so that students would know where to turn for help. These sets of information were specific to each campus. Some sites included links to other campaigns, a place to upload their contact-based educational photos or videos, survey data that highlighted the frequency of stress and mental health problems on campus, social norms messaging, and wellness tools.

Students at each campus also created a large number of awareness raising and health promotion events throughout the year, including, for example, participating in orientation activities, pub nights, coffee houses, and a variety of special events. These included speaker series, panel discussions, seminars, film screenings, promotional giveaways, responsible drinking events, peer support activities and outreach/harm reduction booths. This broad range of activities was designed to increase awareness of mental health resources, rethink 
alcohol use and heavy drinking norms, reduce the stigma associated with help seeking, and examine the issues related to positive and negative masculinities as they pertain to alcohol misuse. Events reached anywhere from small numbers of attendees (under 30) to thousands.

\section{Sustainability}

The sustainability of an intervention project, such as the Caring Campus Project, is always a challenge after the funding ends. Thus, it was important for the project to both develop and implement effective health and wellness strategies, as well as develop structures to sustain them. A core principle was to build capacity for community members to integrate the new program into existing community systems (Wallerstein \& Duran, 2010). Man Up activities were housed in the Student Union Wellness Centre. A key component of the centre's activities was a male-led peer support program (previous peer support workers were female). The young men were trained and provided peer support services through the campus wellness centre. At the close of the Caring Campus Project, the wellness centre incorporated this peer support initiative and now regularly provides male support services. Man Up has also become a campus club, which has helped to ensure its support from the Students' Union. Funding from the Student Affairs office was provided to extend the ProSocial project for another year. For the Boys formalized their group as a campus interest group, which meant that they would receive some funding from student tuition to maintain their activities. Students at two sites who completed Caring Campus surveys were offered a small financial incentive and given the opportunity to donate the funds to project activities. At one site, the co-directors also elected to donate their stipends to this fund.

Finally, on all campuses, members of the Caring Campus team have been invited to take an important role in ongoing student wellness activities.

\section{Knowledge Exchange}

From the beginning of the project, knowledge exchange was considered as a key activity with dedicated funds from the budget. The guiding philosophy was to emphasize knowledge generation and mobilization among participants within the initiative as well as exchange knowledge with other students and stakeholders who were not directly involved in the Caring Campus initiative. A toolkit was designed as an important knowledge exchange resource to assist other post-secondary institutions to address substance misuse and mental health problems within their organizations using the Caring Campus model. The toolkit describes the application of evidence-informed approaches used in the Caring Campus Project. The Substance Use Wellness Tool (see Chen et al., in this special issue) adapted the Mental Health Continuum Model developed by Canada's Department of National Defence (Zamorski, Guest, Bailey, \& Garber, 2012). Focus group data were used to create a continuum of substance use patterns based on particular behavioural cues and consequences rather than actual patterns of use, which reflect a high prevalence of misuse in student populations. Secondly, contact-based educational approaches are described that employ students with lived experience of a substance use problem sharing their experiences about how they have lived with this issue, the real problems they have experienced, and how they came to experience well-being. Key messages to be delivered include hope, acceptance, and the need for early identification and intervention. Finally, the 
toolkit describes how student summits were used to bring student leaders together to learn about substance use and mental health, the availability of local resources, and ways in which they could create sustainable cultural change within their respective campus communities. These activities echo the messages delivered through the contact-based interventions. The critical ingredients of change for this model include youthdriven activities and cultural sensitivity.

A national forum entitled, "Reducing Substance Misuse and Mental Health Problems on Post-Secondary Campuses: Novel Perspectives and Gender-Based Approaches" was held at the close of the project. Two students from each of 10 universities across Canada attended, with costs covered by the project. The idea was that these students would take the lessons learned home with them to their respective campuses. In addition, policymakers, student wellness counsellors, researchers, and funders were represented.

More than 150 people attended the forum, which highlighted gendered approaches to mental health promotion. The forum included keynote addresses from Dr. Michael Kaufman, author and cofounder of the White Ribbon Campaign (who spoke on masculinity, substance use, and mental health on Canadian campuses), Dr. Lorraine Greaves, UBC, Centre of Excellence for Women's Health (who addressed gendertransformative public health applied to substance use and mental health), Joe Ehrmann, former NFL player and cofounder of Building Men and Women for Others, National Fatherhood Initiatives, (who spoke about unhealthy masculinities and their cultural roots and implications), and Jesse Hayman, director of Men's Health Promotion, The Movember Foundation (who spoke of the journey of the Movember Foundation and its vision of ensuring that men live happier, healthier, and longer lives). Workshops and breakout sessions were designed to present tools and provoke discussion related to the lessons learned through the Caring Campus Initiative. All attendees received copies of the Caring Campus Toolkit and resource materials.

Participants completed exit cards to indicate the extent to which they had gained new knowledge because of attending the Forum and formulated specific intentions to share and apply this knowledge on their own campuses. Of the approximately 60 individuals who attended the Closing Reflections session, 54 completed an exit card. Qualitative analysis of the exit card responses yielded eight themes:

1. Taking action. Most participants indicated that they intended to "move to action."

2. Adopting a gender-transformative approach. Most participants reported that they had acquired a new level of awareness with respect to gender, substance use, and mental health as a result of participating in the forum.

3. Encouraging student-led initiatives. Many participants indicated their interest in implementing student-led initiatives on campus to promote men's health.

4. Creating partnerships. Many participants recognized the need to partner with other individuals and groups to develop new ways of approaching men's health.

5. Gaining new insights and understandings. Wellness professionals and students indicated that they had gained new knowledge because of attending the conference.

6. Practical strategies for local implementation. Both wellness professionals and students made mention of the difficulties inherent in translating an approach or model (such as the Caring Campus 
model) to their local context, so they noted the benefit of being able to hear about specific strategies implemented on other campuses.

7. Utilizing resources. Some participants noted their intention to make use of the materials provided through the forum including the Caring Campus Toolkit, presentation slides, and other resources made available by various presenters.

8. Aligning policy and practice. Some participants referred to the fact that bottom-up approaches such as that promoted by the Caring Campus model must also be aligned with system-level administrative policies and practices.

\section{CONCLUSION}

The Caring Campus Project was designed to foster new awareness regarding the interconnections between gender, mental health, and substance misuse, and encourage new approaches to promote men's health. In this project, we demonstrated that male students are willing to assume leadership roles to promote mental health and healthier substance use to their peers, and to enact a social agenda for change. Empowerment strategies encouraged male students to enlist like-minded peers to advance men's mental health and transform campus drinking cultures, including countering gender-based ideals and norms associated with mental health problems and substance misuse. There is now great potential to influence the way in which other post-secondary institutions approach mental wellness and substance misuse using the Caring Campus model, which uses student empowerment to catalyze change.

\section{REFERENCES}

Adlaf, E., Begin, P., \& Sawka, E. (2005). Canadian addiction survey (CAS): A national survey of Canadians' use of alcohol and other drugs: Prevalence of use and related harms: Detailed report. Canadian Centre on Substance Abuse.

Adlaf, E., Demers, A., \& Gliksman, L. (2005). Canadian campus survey 2004. Retrieved from http://www.ontla.on.ca/ library/repository/mon/25005/309709.pdf

Ahern, J., Galea, S., Hubbard, A., Midanik, L., \& Syme, L. (2008). “Culture of drinking” and individual problems with alcohol use. American Journal of Epidemiology, 167(9), 1041-1049.

American College Health Association. (2016). American College Health Association-National college health assessment II: Canadian reference groups data report; Spring 2016. American College Health Association. Hanover, MD: American College Health Association.

Arbour-Nicitopoulos, K., Kwan, M., Lowe, D., Taman, S., \& Faulkner, G. (2010). Social norms of alcohol, smoking, and marijuana use within a Canadian university setting. Journal of American College Health, 59(3), 191-196.

Benson, K., Flory, K., Humphreys, K., \& Lee, S. (2015). Misuse of stimulant medication among college students: A comprehensive review and meta-analysis. Journal of Clinical Child and Family Psychology Review, 18(1), 50-76.

Blank, M.-L., Connor, J., \& Gray, A. (2015). Screening for hazardous alcohol use among university students using individual questions from the Alcohol Use Disorders Identification Test-Consumption. Drug and Alcohol Review, 34(5), 540-548.

Campbell, C., \& Jovchelovitch, S. (2000). Health, community and development: Towards a social psychology of participation. Journal of Community \& Applied Social Psychology, 10(4), 255-270.

Centre for Addiction and Mental Health. (2013). Mental health \& addiction information. Retrieved from http:// www.camh.ca/en/hospital/health_information/a_z_mental_health_and_addiction_information/Pages/default. aspx? select $=\mathrm{A}$ 
Chen, S.-P., Dobson, K., Kirsh, B., Knaak, S., Koller, M., Krupa, T., . . Szeto, A. (2017). Fighting stigma in Canada: Opening minds anti-stigma initiatives. In W. Gaebel, N. Sartorius, \& W. Rossler (Eds.), The stigma of mental illness - End of the story? (pp. 237-261). New York: Springer International Publishing.

Chen, S.-P., Stuart, H., Krupa, T., Dobson, K., \& Stewart, S. (in press). The development and psychometric testing of a substance use wellness tool. Canadian Journal of Community Mental Health, 37(3).

Clark, C., \& Krupa, T. (2002). Reflections on empowerment in community mental health: Giving shape to an elusive idea. Psychiatric Rehabilitation, 25(4), 341-349.

Cooper, S. (1999). Changing the campus drinking culture: An initiator-catalyst consultation approach. Consulting Psychology Journal: Practice and Research, 51(3), 160-169.

Corrigan, P., Faber, D., Rashid, F., \& Leary, M. (1999). The construct validity of empowerment among consumers of mental health services. Schizophrenia Research, 38(1), 77-84.

Corrigan, P., Morris, S., Michaels, P., Rafacz, J., \& Rusch, N. (2012). Challenging the public stigma of mental illness: A meta-analysis of outcome studies. Psychiatric Services, 63(10), 963-973.

Das, J., Salam, R., Arshad, A., Finkelstein, Y., \& Bhutta, Z. (2016). Interventions for adolescent substance abuse: An overview of systematic reviews. Journal of Adolescent Health, 59(4[Suppl]), S61-S75.

Downey, L., Anyaegbunam, C., \& Scutchfield, F. (2009). Dialogue to deliberation: Expanding the empowerment education model. American Journal of Health Behavior, 33(1), 26-36.

Dowson, K. A., Schneider, M. A., Fletcher, P. C., \& Bryden, P. J. (2007). Examining gender differences in the health behaviors of Canadian university students. The Journal of the Royal Society for the Promotion of Health, 127(1), $38-44$.

Eisenberg, D., Downs, M. F., Golberstein, E., \& Zivin, K. (2009). Stigma and help seeking for mental health among college students. Medical Care Research and Review, 66(5), 522-541.

Government of Canada. (2017). Canadian tobacco alcohol and drugs (CTADS): 2015 survey. Retrieved from Canada.ca

Hagman, B., Noel, N., \& Clifford, P. (2007). Social norms theory-based interventions: Testing the feasibility of a purported mechanism of action. Journal of American College Health, 56(3), 293-298.

Health Canada. (2008). Canadian addiction survey (CAS): A national survey of Canadians' use of alcohol and other drugs - Focus on gender. Ottawa: Health Canada.

Ibrahim, A. K., Kelly, S. J., Adams, C. E., \& Glazebrook, C. (2013). A systematic review of studies of depression prevalence in university students. Journal of Psychiatric Research, 47(3), 391-400.

Johnston, L., O'Malley, P., Bachman, J., Schulenbergt, J., \& Miech, R. (2016). Monitoring the future. National survey results on drug use, 1975-2015. Volume 2. College students \& adults ages 19-55. Ann Arbor: Institute for Social Research, The University of Michigan.

Keyes, K. M., Hatzenbuehler, M. L., Grant, B. F., \& Hasin, D. H. (2012). Stress and alcohol. Alcohol Research, 34(4), 391-400.

Lalomiteanu, A., Adlaf, E., Mann, R., \& Rehm, J. (2011). CAMH monitor eReport: Addiction and mental health indicators among Ontario adults, 1997-2009. Toronto: Centre for Addictions and Mental Health.

Laverack, G., \& Labonte, R. (2000). A planning framework for community empowerment goals within health promotion. Health Policy and Planning, 15(3), 255-262.

Leatherdale, S., \& Burkhalter, R. (2012). The substance use profile of Canadian youth: Exploring the prevalence of alcohol, drug, and tobacco use by gender and grade. Addictive Behaviours, 37(3), 318-322.

Marko, T., \& Watt, T. (2011). Employing a youth-led adult-guided framework. Family and Community Health, 34(4), 319-330.

Mathie, A., \& Cunningham, G. (2005). Who is driving development? Reflections on the transformative potential of asset-based community development. Canadian Journal of Development Studies, 25(1), 175-186.

Misch, D. (2010). Changing the culture of alcohol abuse on campus: Lessons learned from secondhand smoke. Journal of American College Health, 59(3), 232-234.

Oliffe, J. L., Ogrodniczuk, J. S., Gordon, S. J., Creighton, G., Kelly, M. T., Black, N., \& Mackenzie, C. (2016). Stigma in male depression and suicide: A Canadian sex comparison study. Community Mental Health Journal, 52(3), 302-310.

Reavley, N., \& Jorm, A. F. (2010). Prevention and early intervention to improve mental health in higher education students: A review. Early Intervention in Psychiatry, 4(2), 132-142. 
Reis, J., \& Riley, W. (2008). First-year students' views on changing their campus alcohol culture. NASPA Journal, 45(2), 192-209.

Rogers, S., Chamberlain, J., Ellison, M., \& Crean, T. (1997). A consumer-constructed scale to measure empowerment among users of mental health services. Psychiatric Services, 48(8), 1042-1047.

Scott-Sheldon, L., Carey, K., Elliott, J., Garey, L., \& Carey, M. (2014). Efficacy of alcohol interventions for first-year college students: A meta-analytic review of randomized controlled trials. Journal of Consulting and Clinical Psychology, 82(2), 177-188.

Stone, A., Becker, L., Huber, A., \& Catalano, R. (2012). Review of risk and protective factors of substance use and problem use in emerging adulthood. Addictive Behaviors, 37(7), 747-775.

Stuart, H., Koller, M., Christie, R., \& Pietrus, M. (2011). Reducing mental health stigma: A case study. Healthcare Quarterly, 14(Special Issue [April]), 41-49.

Valdivia, I., \& Stewart, S. (2005). Further examination of the psychometric properties of the comprehensive effects of alcohol questionnaire. Cognitive Behaviour Therapy, 34(1), 22-33.

Wallerstein, N., \& Duran, B. (2010). Community-based participatory research contributions to intervention research: The intersection of science and practice to improve health equity. American Journal of Public Health, 100(Suppl. 1), S40-S46.

Wechsler, H., \& Nelson, T. (2008). What we have learned from the Harvard School of Public Health College Alcohol Study: Focusing attention on college student alcohol consumption and the environmental conditions. Journal of Studies on Alcohol and Drugs, 69(4), 481-490.

White, A., Kraus, C., \& Swartzwelder, S. (2006). Many college freshmen drink at levels far beyond the binge threshold. Alcoholism: Clinical and Experimental Research, 30(6), 1006-1010.

Wicki, M., Kuntsche, E., \& Gmel, G. (2010). Drinking at European universities? A review of students' alcohol use. Addictive Behaviors, 35(11), 913-924.

Yoshimoto, H., Takayashiki, A., Goto, R., Saito, G., Kawaida, K., Hieda, R., . . Takemura, Y. (2017). Association between excessive alcohol use and alcohol-related injuries in college students: A multi-centre cross sectional study in Japan. The Tohoku Journal of Experimental Medicine, 242, 157-163.

Zamorski, M. G. K., Bailey, S., \& Garber, B. (2012). Beyond battlemind: Evaluation of a new mental health training program for Canadian forces personnel participating in third-location decompression. Military Medicine, 177(11), $1245-1253$. 